\title{
Human Chondrosarcoma Cells Acquire an Epithelial-Like Gene Expression Pattern via an Epigenetic Switch: Evidence for Mesenchymal-Epithelial Transition During Sarcomagenesis
}

\author{
Matthew P. Fitzgerald, ${ }^{1}$ Francoise Gourronc, ${ }^{2}$ Melissa L. T. Teoh, ${ }^{1}$ Matthew J. Provenzano, ${ }^{3}$ \\ Adam J. Case, ${ }^{1}$ James A. Martin, ${ }^{2}$ and Frederick E. Domann ${ }^{1}$ \\ ${ }^{1}$ Free Radical and Radiation Biology Program, Department of Radiation Oncology, University of Iowa, Iowa City, IA 52242, USA \\ ${ }^{2}$ Department of Orthopaedics and Rehabilitation, University of Iowa, Iowa City, IA 52242, USA \\ ${ }^{3}$ Department of Otolaryngology-Head and Neck Surgery, University of Iowa, Iowa City, IA 52242, USA
}

Correspondence should be addressed to Frederick E. Domann, frederick-domann@uiowa.edu

Received 15 September 2010; Accepted 20 January 2011

Academic Editor: Stephen Lessnick

Copyright (C) 2011 Matthew P. Fitzgerald et al. This is an open access article distributed under the Creative Commons Attribution License, which permits unrestricted use, distribution, and reproduction in any medium, provided the original work is properly cited.

\begin{abstract}
Chondrocytes are mesenchymally derived cells that reportedly acquire some epithelial characteristics; however, whether this is a progression through a mesenchymal to epithelial transition (MET) during chondrosarcoma development is still a matter of investigation. We observed that chondrosarcoma cells acquired the expression of four epithelial markers, E-cadherin, desmocollin 3, maspin, and 14-3-3 $\sigma$, all of which are governed epigenetically through cytosine methylation. Indeed, loss of cytosine methylation was tightly associated with acquired expression of both maspin and 14-3-3 $\sigma$ in chondrosarcomas. In contrast, chondrocyte cells were negative for maspin and 14-3-3 $\sigma$ and displayed nearly complete DNA methylation. Robust activation of these genes was also observed in chondrocyte cells following 5-aza-dC treatment. We also examined the transcription factor snail which has been reported to be an important mediator of epithelial to mesenchymal transitions (EMTs). In chondrosarcoma cells snail is downregulated suggesting a role for loss of snail expression in lineage maintenance. Taken together, these results document an epigenetic switch associated with an MET-like phenomenon that accompanies chondrosarcoma progression.
\end{abstract}

\section{Introduction}

Chondrosarcoma is a rare but deadly form of bone cancer and is the second most common type of bone cancer accounting for nearly $26 \%$ of all bone cancers [1]. These tumors are stubbornly resistant to both chemotherapy and radiation therapy, therefore surgical ablation is still the most effective treatment $[2,3]$. However since surgical resection is often difficult and not practical for metastatic disease, more effective treatments are needed.

Chondrosarcomas have been presumed to arise from the chondrocyte lineage of mesenchymal cells; of mesodermal origin because they are the most similar cells however, the exact origin or subtype of cells is still an area of active investigation. Numerous studies have shown the occurrence of genetic alterations in chondrosarcomas including loss of heterozygosity ( $\mathrm{LOH}$ ) on multiple chromosomes, wide variation in ploidy status, and mutations in the tumor suppressors p53, p16ink4a, pRB, among others [4-6]. In contrast, relatively little is known about the epigenetic alterations that occur during chondrosarcoma progression $[7,8]$.

The malignant progression to chondrosarcoma has been suggested to involve some degree of a mesenchymal to epithelial transition (MET), and it has been shown in an in vitro model that chondrosarcoma cells can transition to a more epithelial-like phenotype under certain conditions [9]. MET is a fundamental developmental process which is important to vertebrate embryogenesis in vascular, urinary, and genital tissues $[10,11]$. Although much has been learned about the more commonly known and well-studied reciprocal process, the epithelial to mesenchymal transition 
(EMT) during carcinoma progression, the mesenchymal to epithelial transition (MET) in sarcoma progression is considerably less well understood. These lineage transitions have important consequences to cell morphology, cell to cell adhesion, cell motility, and in the extracellular matrix of cells. However, the phenotypic plasticity conferred to cells as a result of these transitions which are so critical to development may also become coopted by cells during the process of carcinogenesis.

MET during carcinogenesis has been shown to be induced by the c-met proto-oncogene $[9,12,13]$. P140 cmet is a receptor tyrosine kinase for HGF/SF and increased expression leads to epithelial differentiation $[14,15]$. In addition to epithelial specification by $c$-met, 5 -azacytidine, a DNA methyltransferase inhibitor with broad spectrum epigenetic effects, has been used to induce the conversion of mesenchymal cells into epithelial cells in vitro [16]. More recently research on the transcription factor snail has been linked to aberrant DNA methylation of the epithelial specific E-cadherin promoter in association with EMT, and stable RNA interference of snail expression in carcinoma cell lines induced a complete MET [17, 18]. Finally, as corneal stromal keratinocytes differentiate into corneal fibroblasts they undergo an epigenetic switch with respect to maspin expression [19]. Such results highlight the possible role played by epigenetic changes through DNA methylation in a cell's ability to transdifferentiate from a mesenchymal to a more epithelial phenotype.

To investigate whether chondrosarcoma cells are displaying some characteristics of MET we examined four epithelial markers to confirm the acquisition of more epithelial-like expression. These epithelial markers included E-cadherin, desmocollin 3, maspin, and 14-3-3 $\sigma$. Next to investigate whether epigenetic changes are occurring in chondrosarcomas we examined protein and RNA expression along with the DNA methylation at two distinct and separate loci, maspin and 14-3-3 $\sigma$. Both have been identified as specific epithelial markers and have separately been shown in lung, pancreas, prostate, and other cancers to be epigenetically controlled through DNA methylation [20-24]. Finally we measured expression of the snail transcription factor which has been reported to be an important mediator of EMT in part through epigenetic mechanisms [25].

Maspin is a member of the serpin family of protease inhibitors (SERPINB5) and has been described as an epithelial marker and a type II tumor suppressor gene based upon its ability to inhibit invasion and motility of mammary tumors [26-29]. Zhang and colleagues also found maspin to function as an inhibitor of angiogenesis [28, 30, 31]. Maspin gene expression is regulated in part through methylation of its promoter in human normal cells [29]. In addition, silencing of the maspin gene in association with aberrant DNA methylation has been reported in cancer cells from breast, melanoma, and thyroid [20, 32, 33]. Nevertheless, loss of maspin expression in cancer is not a universal phenomenon. In other malignancies such as pancreatic, lung, ovarian, and gastric cancers, maspin expression is paradoxically increased in malignant cells compared to their normal cells of origin $[21,34-36]$.
14-3-3 $\sigma$, also known as stratifin or HME1, was originally identified as an epithelial-specific marker downregulated in breast cancer cell lines [37]. 14-3-3 $\sigma$ has been shown to be involved in a wide variety of cellular processes, including its response to DNA damaging agents and gamma radiation through activation by p53, which then contributes to G2 cell cycle arrest $[38,39]$. Studies have shown that, similar to maspin, downregulation of $14-3-3 \sigma$ was associated with aberrant hypermethylation of the $14-3-3 \sigma$ CpG island [23, $40,41]$. Since the original report, hypermethylation of $14-$ 3-3 $\sigma$ leading to silencing has been reported in prostate, hepatocellular carcinomas, and others [23, 41]. However, just

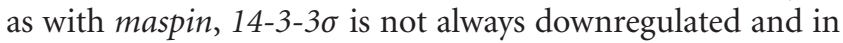
fact is upregulated in pancreas and squamous cell carcinomas $[42,43]$.

Two members of the cadherin family of cell adhesion molecules E-cadherin and desmocollin 3, have been shown to be downregulated in several types of cancers through DNA methylation $[44,45]$. This decrease in expression has been correlated with the epithelial to mesenchymal transition. The snail transcription factor has been shown to repress E-cadherin expression and has been reported to be an important mediator of epithelial to mesenchymal transitions. Recently, it has been shown that snail binds to the E-boxes of the E-cadherin promoter and can recruit the histone deacetylase HDAC1 and DNA methyltransferase DNMT1 to help in the epigenetic silencing of E-cadherin [46].

In this study we show an upregulation of four distinct epithelial markers and the downregulation of snail, all consistent with cells that have undergone to some extent an MET transition. Next we show that epigenetic alterations in two of these genes, maspin and 14-3-3 $\sigma$, are consistent with their gain of expression in chondrosarcomas. We demonstrate that loss of DNA methylation at both the maspin and 14$3-3 \sigma$ loci led to increased expression of these two epithelial specific genes during chondrosarcoma carcinogenesis. These results link the mesenchymal to epithelial transition in chondrosarcoma to an epigenetic switch in lineage-specific gene expression.

\section{Materials and Methods}

2.1. Cell Culture. Chondrosarcoma cells and normal chondrocytes were isolated by overnight digestion of chopped tissues with $0.5 \mathrm{mg} / \mathrm{mL}$ type IA collagenase and pronase E (Sigma) in Dulbecco Modified Eagle's medium with $10 \%$ fetal calf serum (Life Technologies). All cells were cultured as monolayers in growth medium containing 40\% Dulbecco Modified Eagle's medium, 40\% Minimum Essential medium, 20\% Ham's F12, 10\% fetal calf serum supplemented with $1.0 \mathrm{units} / \mathrm{ml}$ insulin, $20 \mu \mathrm{g} / \mathrm{mL}$ hydrocortizone (Sigma), and $40 \mu \mathrm{g} / \mathrm{mL}$ gentamycin or $100 \mathrm{units} / \mathrm{ml}$ penicillin/streptomycin and grown at $37^{\circ} \mathrm{C}$ with $5 \% \mathrm{CO}_{2}$ in a humidified cell culture incubator. The SNM83 are the normal chondrocyte cell strain used in this study. The cell line JJ was a generous gift from Dr. Joel Block. The in vitro morphologies of several of these cell lines 
have been previously reported [47]. Briefly, we found that the in situ morphology of chondrocytes and low-grade chondrosarcoma cells changed in monolayer culture, where both transitioned from a spindle cell shape to a more polygonal cell shape after a few passages. High-grade (2-3) chondrosarcoma cells in monolayer culture retained their spindle shaped in culture.

2.2. Real-Time RT-PCR Assays for Gene Expression. Total cellular RNA was isolated using RNeasy Mini Kit (Qiagen, Valencia, CA, USA) and quantified using a biophotometer (Eppendorf, Westbury, NY, USA). For real-time RTPCR analysis of maspin and 14-3-3o mRNA expression, a reverse transcription step was performed using a High Capacity cDNA Archive Kit (Applied Biosystems Inc., Foster City, CA, USA). The reverse transcription reaction of $2 \mu \mathrm{g}$ of RNA was primed with random primers and incubated at $25^{\circ} \mathrm{C}$ for $10 \mathrm{~min}$ followed by $37^{\circ} \mathrm{C}$ for $120 \mathrm{~min}$. The primer/probe PCR reactions consisted of $100 \mathrm{ng}$ of cDNA added to $12.5 \mu \mathrm{L}$ of TaqMan Universal PCR Master Mix (Applied Biosystems Inc.), $1.25 \mu \mathrm{L}$ of gene-specific maspin and 14-3-3 $\sigma$ primer/probe mix (Assays-on-Demand, Applied Biosystems Inc.), and $6.25 \mu \mathrm{L}$ PCR grade water, for a $25 \mu \mathrm{L}$ total reaction. For E-cadherin, desmocollin 3, and snail the primers were designed using $\mathrm{ABI}$ primer express software. Primer sequences are available upon request. The PCR reactions consisted of $100 \mathrm{ng}$ cDNA with $0.6 \mu \mathrm{M}$ primers in Power SYBR green PCR MasterMix (Applied Biosystems Inc.) with a total reaction volume of $25 \mu \mathrm{L}$. The genes were not multiplexed but rather amplified in separate tubes. The PCR conditions for all reactions were $95^{\circ} \mathrm{C}$ for $10 \mathrm{~min}$, followed by 40 cycles of $95^{\circ} \mathrm{C}$ for $15 \mathrm{~s}$, with annealing at $60^{\circ} \mathrm{C}$ for $1 \mathrm{~min}$. Real-Time PCR was performed on an ABI 7000 real-time sequence detection system. Both the maspin and 14-3-3 $\sigma$ gene-specific TaqMan probes were labeled with a $5^{\prime}$ reporter dye, 6-FAM, and a $3^{\prime}$ end containing a nonfluorescent quencher and a minor groove binder. Fold differences in mRNA expression were calculated using their respective mRNA expression calibrated to 18-s ribosomal RNA expression and computed using ABI relative quantitation software (Applied Biosystems Inc.).

2.3. Western Blot Analysis. Proteins were isolated from SNM83 and NH69 cells using RIPA buffer and quantified using a Bradford assay. Twenty $\mu \mathrm{g}$ of protein were size fractionated by electrophoresis on a $12 \%$ SDS-PAGE gel and then transferred to nitrocellulose membranes. The membranes were then probed with a maspin antibody (Pharmingen) and 14-3-3 $\sigma$ antibody (Chemicon).

2.4. Sodium Bisulfite Genomic DNA (gDNA) Sequencing. Genomic DNA was isolated using the DNeasy Tissue Kit (Qiagen, Valencia, CA, USA) and quantified using a biophotometer (Eppendorf). Five micrograms of genomic DNA was modified under conditions previously described [32]. The maspin and 14-3-3 $\sigma$ CpG islands were amplified from the bisulfite modified DNA by two rounds of PCR utilizing nested PCR primers specific to the bisulfite mod-

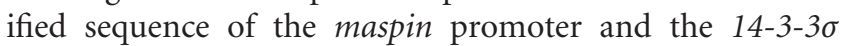
CpG island as described previously $[32,48]$. The final PCR product was cloned into a TOPO TA vector according to the manufacturer's instructions (TOPO TA Cloning Kit, Invitrogen, Carlsbad, CA, USA). Five positive recombinants were isolated using Qiaprep Spin Plasmid Miniprep Kit (Qiagen) according to manufacturer's instructions and sequenced on an ABI automated DNA sequencer. The methylation status of individual $\mathrm{CpG}$ sites was determined by comparison of the sequence obtained with the known maspin and 14-3$3 \sigma$ sequences. The number of methylated CpGs at a specific site was divided by the number of clones analyzed $(n=$ $5)$ to yield the percent methylation for each site. For total promoter methylation calculation, the total of all the $19 \mathrm{CpG}$

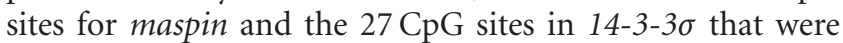
methylated from the 5 clones was counted and divided by the total $\mathrm{CpG}$ sites.

2.5. Gene Reactivation Using 5-Aza-2'-Deoxycytidine. For 5aza- 2 -deoxycytidine $(5$-aza- $\mathrm{dC})$ reactivation studies in the CS8E chondrosarcoma cell line, cells were plated at $5 \times$ 104 cells in 6-well plates and were treated with $10 \mu \mathrm{M} \mathrm{5}$-aza$\mathrm{dC}$ in complete media on days 0,2 , and 4 then harvested for total RNA on day 5 using an RNeasy Mini Kit (Qiagen, Valencia, CA, USA). RNA was then analyzed by real-time RTPCR.

\section{Results}

3.1. Gain of mRNA Expression of Epithelial-Specific Genes in Chondrosarcomas. Compared to normal chondrocytes, chondrosarcoma cell lines displayed gain of expression of several epithelial-specific markers. E-cadherin mRNA expression was significantly upregulated in 4 of the 5 chondrosarcoma cell lines ranging from a 6 - to 189 -fold induction over the normal SNM83 normal chondrocyte cell strain as shown in Figure 1(a). Similarly, desmocollin 3 mRNA expression was acquired in 4 of the 5 cell lines examined, ranging from a 2to a 12 -fold increase as compared to the normal counterpart SNM83, as shown in Figure 1(b). Maspin mRNA levels were also similarly affected. Maspin mRNA expression was virtually undetectable in the normal SNM83 chondrocyte cell strain and in stage I early CS8E chondrosarcoma cell line. In contrast, the chondrosarcoma cells CSPG, JJ, NH69, and $\mathrm{CS} 13 \mathrm{H}$ displayed abundant maspin expression as shown in Figure 2(a) and Table 1. The chondrosarcoma cell lines displayed approximately $10^{2}$ - to $10^{5}$-fold higher levels of maspin mRNA expression when compared to the normal SNM83 chondrocyte cell line. Finally, we determined that 14-3-3 $\sigma$ mRNA expression was also virtually undetectable in the SNM83 normal chondrocyte cell strain and in CS8E cancer cell line and low in the CSPG cell line. In the other chondrosarcoma cells JJ, NH69, and CS13H there was approximately 100-fold higher levels of 14-3-3 $\sigma$ mRNA expression as shown in Figure 2(b) and Table 1. To our knowledge this is the first report showing the upregulation of either maspin or $14-3-3 \sigma$ in chondrosarcoma cell lines. 


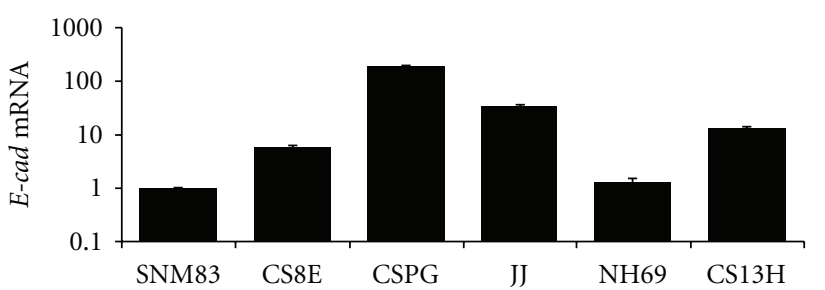

(a)

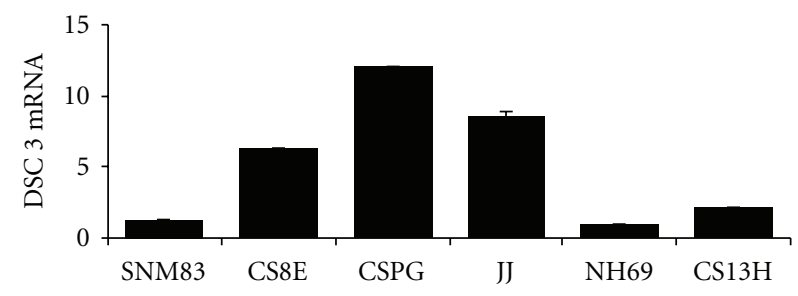

(b)

FIGURE 1: Chondrosarcomas acquire aberrant expression of epithelial-specific genes E-cadherin and desmocollin-3. (a) E-cadherin mRNA expression was measured by real-time PCR. Four of the five chondrosarcoma cell lines (CS8E, CSPG, JJ, and CS13H) showed a significant increase in E-cadherin mRNA expression from approximately 6- to 189-fold increase when compared to the normal SNM83 chondrocyte cell line. SNM83 had minimal expression but was set at 1 on graph as calculated using $\Delta \Delta$ CT relative quantification method. (b) Desmocollin 3 mRNA expression was measured by real-time PCR. Four of the five chondrosarcoma cell lines (CS8E, CSPG, JJ, and CS13H) showed a significant increase from approximately 1.5- to 12-fold more Desmocollin 3 mRNA when compared to normal line. Again SNM83 had minimal expression but was arbitrarily set at 1 for calculation purposes.

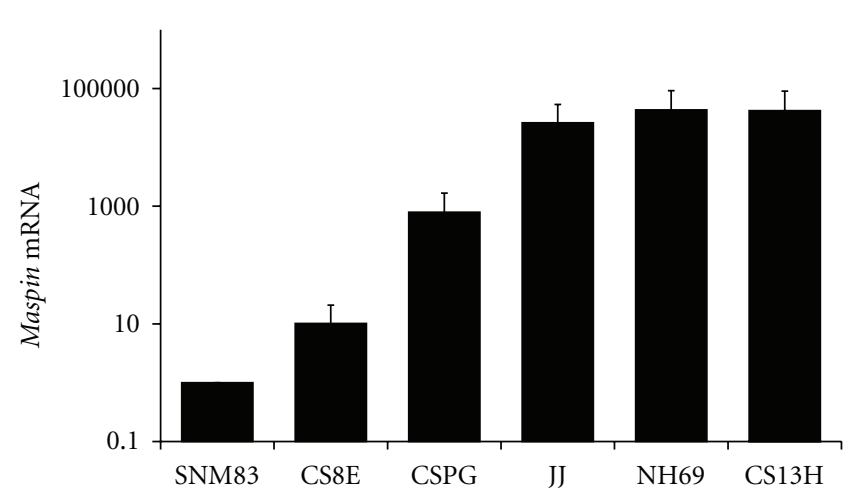

(a)

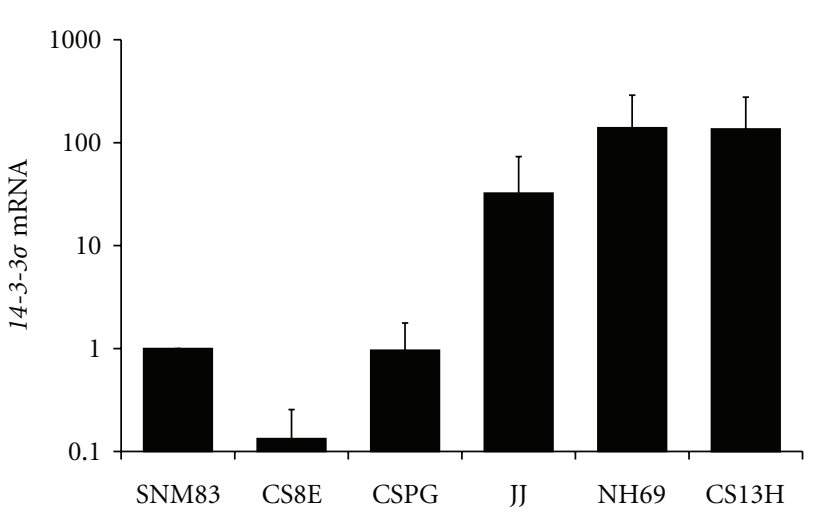

(b)

FIGURE 2: Chondrosarcomas acquire aberrant expression of epithelial-specific genes maspin and 14-3-3 $\sigma$. (a) Maspin mRNA expression was measured by real-time PCR. Four of the five chondrosarcoma cell lines (CSPG, JJ, NH69, and CS13H) showed a significant increase in maspin mRNA expression when compared to the normal SNM83 chondrocyte cell line. SNM83 had minimal expression but was set at 1 on graph as calculated using $\Delta \Delta$ CT relative quantification method. (b) 14-3-3 $\sigma$ mRNA expression was measured by real-time PCR. Three of the five chondrosarcoma cell lines (JJ, NH69 and CS13H) showed a significant increase from approximately 50- to 150-fold more 14-3-3 $\sigma$ mRNA when compared to normal SNM83 and the CS8E and CSPG chondrosarcoma cell lines. Again SNM83 had minimal expression but was arbitrarily set at 1 for calculation purposes.

TABLE 1: Summary of maspin and 14-3-3 $\sigma$ mRNA expression and cytosine methylation states in human chondrosarcoma cell lines.

\begin{tabular}{|c|c|c|c|c|}
\hline Cell Line & Expression & Fold change mRNA & Methylation & $\%$ Methylation \\
\hline \multicolumn{5}{|l|}{ Maspin } \\
\hline SNM83 & - & 1 & + & 93 \\
\hline CS8E & - & 10 & + & 86 \\
\hline CSPG & + & 1000 & - & 7 \\
\hline JJ & + & 32,000 & - & 3 \\
\hline NH69 & + & 63,000 & - & 1 \\
\hline $\mathrm{CS} 13 \mathrm{H}$ & + & 63,000 & $+/-$ & 65 \\
\hline \multicolumn{5}{|l|}{$14-3-3 \sigma$} \\
\hline SNM83 & - & 1 & + & 85 \\
\hline CS8E & - & .15 & + & 90 \\
\hline CSPG & - & 1 & + & 95 \\
\hline JJ & + & 45 & - & 27 \\
\hline NH69 & + & 150 & - & 6 \\
\hline $\mathrm{CS} 13 \mathrm{H}$ & + & 145 & - & 4.4 \\
\hline
\end{tabular}




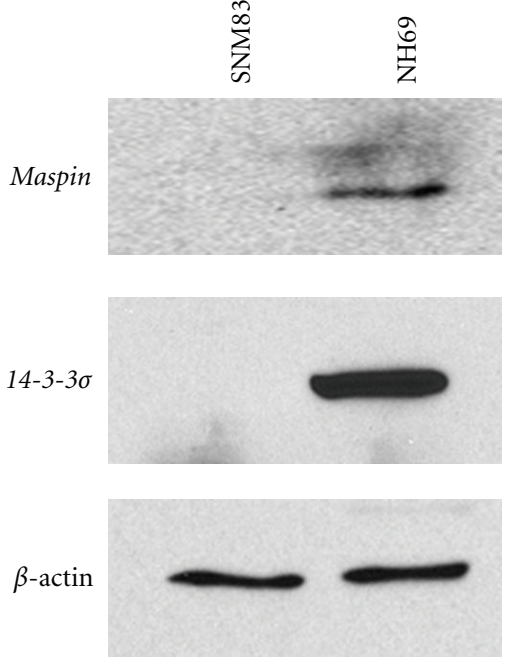

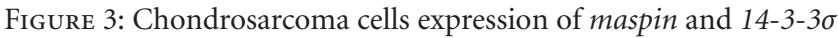
proteins. Western blot analysis for maspin and $14-3-3 \sigma$. Lane 1 is the SNM83 chondrocyte cell line which shows no protein expression for either maspin or 14-3-3 $\sigma$, and in lane 2 the NH69 chondrosarcoma cell line shows a robust induction of both proteins. These are consistent with real-time PCR results of mRNA expression. Betaactin was used as the loading control.

3.2. Gain of Epithelial-Specific Protein Expression. To determine whether the increases in mRNA observed were translated into functional proteins we performed western blotting on the epithelial-specific markers maspin and $14-3-3 \sigma$ in two representative cell lines as shown in Figure 3. The normal SNM83 cells showed no detectable expression of maspin or 14-3-3 $\sigma$ while the chondrosarcoma cell line NH69 showed robust expression of both proteins consistent with the previously observed upregulation in the maspin and 143-3б's mRNA levels (Figure 2).

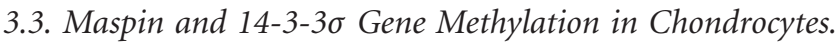
Figures 4(a) and 4(b) represent the normal methylated state of the maspin promoter in the normal chondrocyte cell line SNM83. Figure 4(a) is a histogram representing the percent methylation at each of the $19 \mathrm{CpG}$ locations and their distribution across the maspin promoter' whereas Figure 4(b) shows the five analyzed clones individually and the methylation at each CpG site. The overall methylation for the maspin promoter was $93 \%$ in the SNM83 cells (Table 1). This high degree of promoter methylation taken along with the undetectable SNM83 maspin mRNA and protein levels represented in Figures 2(a) and 3 is consistent with reported studies linking high maspin promoter methylation with silenced gene expression.

Figures 4(c) and 4(d) represent the methylation status of 27 CpG's in the 14-3-3 $\sigma$ gene in the SNM83 cells. Similar to the maspin promoter, 14-3-3 $\sigma$ shows a highly methylated state of the CpG's in normal 14-3-3 $\sigma$ negative chondrocytes. Figure $4(\mathrm{c})$ is a histogram representing the overall percent methylation from the five picked clones at each CpG site and its distribution across the gene; whereas Figure 4(d)

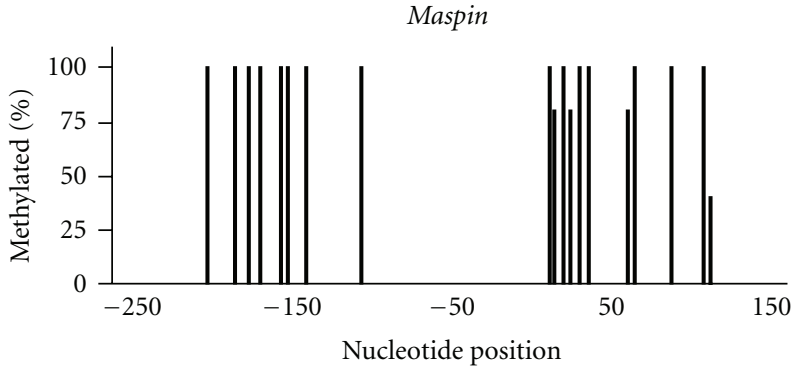

(a)

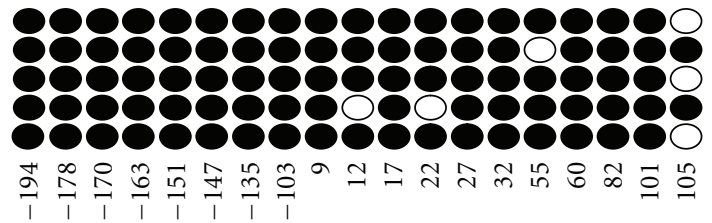

Nucleotide position

(b)

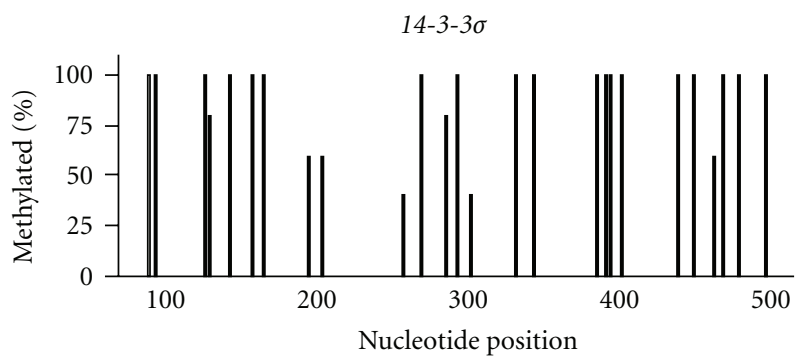

(c)

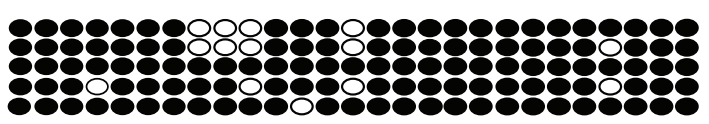

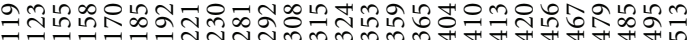

Nucleotide position

(d)

FIGURE 4: Normal chondrocyte cells have a highly methylated maspin promoter and 14-3-3 $\sigma \mathrm{CpG}$ island. (a) and (c) Histograms representing the percent methylation at each of the CpG's spanning the maspin promoter and $14-3-3 \sigma \mathrm{CpG}$ island in SNM83 chon-

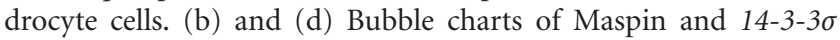
in SNM83. Each of the five rows represents a sequenced amplicon, while each of the columns represents the position of the nucleotide relative to the transcription start site. Darkened circles represent methylated cytosines while open circles represent unmethylated cytosines. Nucleotide positions relative to start site were based on UCSC genome browser build 17 .

shows the individual clones and methylation at each $\mathrm{CpG}$ site. The overall methylation of SNM83 from the sequenced clones is $85 \%$ methylated. This methylation pattern of $14-$ 3-3 $\sigma$, similar to maspin, is associated with silenced $14-3-3 \sigma$ expression.

3.4. Loss of Maspin Promoter Methylation in Human Chondrosarcomas. Figure 5(a) illustrates the methylation frequency and distribution at each of the $19 \mathrm{CpG}$ 's we measured 


$$
\begin{gathered}
\text { Maspin } \\
\text { CS8E }
\end{gathered}
$$

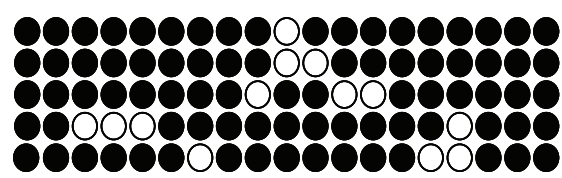

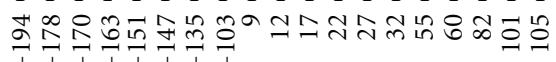

NH69

0000000000000000000

ODO0000000000000000

oOOOOOOOOOOOOOOOOOO

0000000000000000000

000000000000000000

목

CSPG

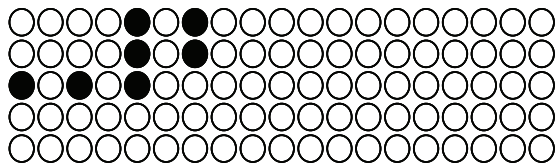

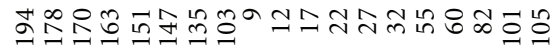

। 1 । 1 ।

$\mathrm{JJ}$

0000000000000000000 0000000000000000000 0000000000000000000 0000000000000000000 000000000000000000

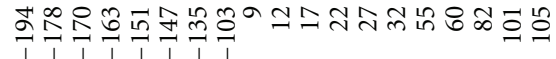

$\mathrm{CS} 13 \mathrm{H}$

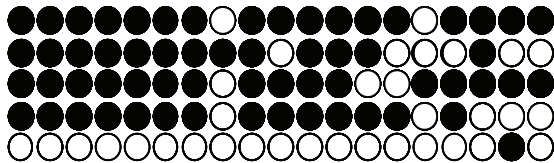

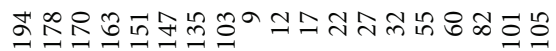

(a)
$14-3-3 \sigma$

CS8E

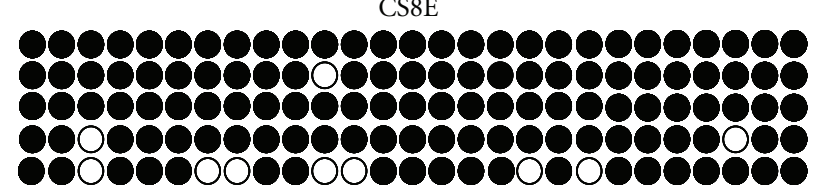

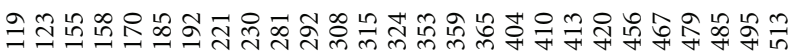

NH69

000000000000000000000000000 000000000000000000000000000 000000000000000000000000000 000000000000000000000000000 000000000000000000000000000

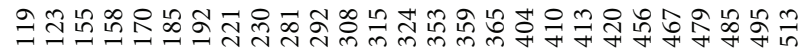

CSPG

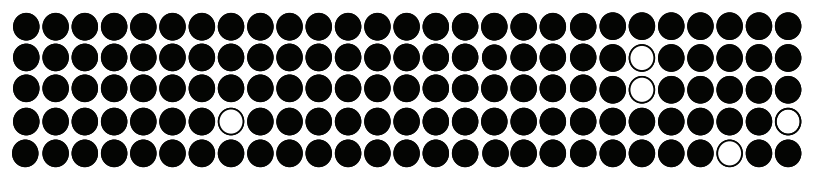

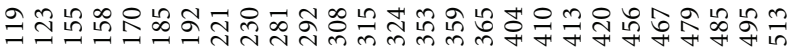

\section{$\mathrm{JJ}$}

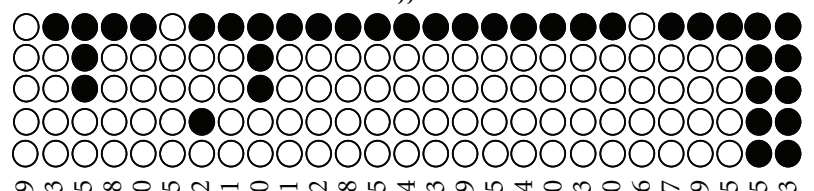

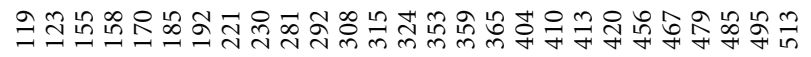

$\mathrm{CS} 13 \mathrm{H}$

000000000000000000000000000 000000000000000000000000000 ○00000000000000000000000000 ○o0000000000000000000000000 000000000000000000000000000

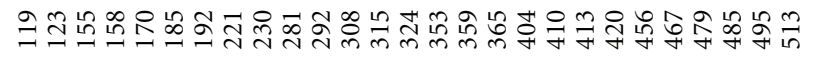

(b)

FIGURE 5: The maspin promoter and 14-3-3 $\sigma$ gene are hypomethylated in mRNA expressing chondrosarcoma cell lines. Bubble charts of

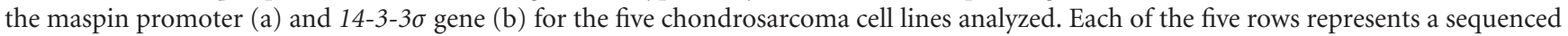
amplicon while each column represents the nucleotide position of the CpG measured relative to the transcription start site. Darkened circles represent methylated cytosines, and clear circles represent unmethylated cytosines. Nucleotide positions relative to start site were based on UCSC genome browser build 17.

in the maspin promoter in the five human chondrosarcoma cell lines analyzed. SNM83 (Figure 4) and CS8E displayed overall maspin promoter methylation percentages of $93 \%$ and $86 \%$, respectively, while $\mathrm{CS} 13 \mathrm{H}$ showed an intermediate methylation percentage of $65 \%$. In sharp contrast, the remaining chondrosarcoma cell lines CSPG, JJ, and NH69 displayed significantly lower percentages of overall promoter methylation of $7 \%, 3 \%$, and $1 \%$ respectively (Table 1 ). The intermediate promoter methylation of $\mathrm{CS} 13 \mathrm{H}$ may be due to the phenotypic heterogeneity displayed in the tumor tissue from which the DNA was extracted (data not shown), or could be due to a reversion of this late stage chondrosarcoma back to a more "normal" methylation profile similar to chondrocytes. Nonetheless, these data are consistent with our 

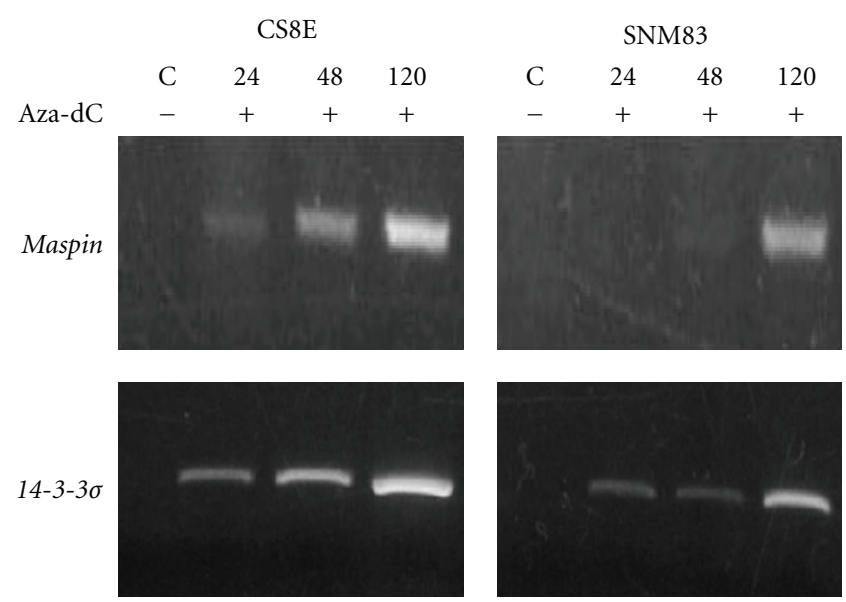

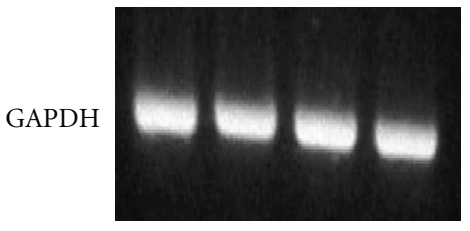

Chondrosarcoma

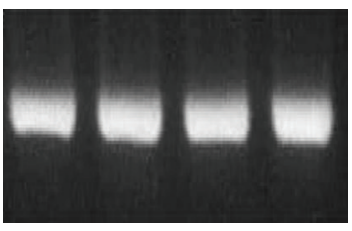

Chondrocytes
Figure 6: The methyltransferase inhibitor 5-Aza-dC reactivated both maspin and 14-3-3 $\sigma$ mRNA expression in chondrocytes and chondrosarcomas cell lines. The CS8E chondrosarcoma cell line and SNM83 normal chondrocyte cell line were exposed to $10 \mathrm{uM} 5$-AzadC. RNA was harvested after 48, 72, and 120 hours and subjected to RT-PCR for maspin and 14-3-3 $\sigma$. GAPDH was used as loading control.

previous report in human pancreatic carcinoma cell lines as well as reports from human breast, lung, ovarian, and thyroid cancers that tightly associate maspin expression to promoter methylation.

3.5. 14-3-3 $\sigma$ Gene Methylation in Chondrosarcomas. Figure 5(b) also illustrates the methylation frequency and distribution at each of the $27 \mathrm{CpG}$ sites of the $14-3-3 \sigma \mathrm{CpG}$ island among the sequenced amplicons from the same five chondrosarcoma cell lines. CS8E and CSPG displayed a percentage of overall DNA methylation of $90 \%$ and $95 \%$, respectively. In contrast, the remaining chondrosarcomas cell lines display relatively little DNA methylation (Table 1). This supports previous work with $14-3-3 \sigma$ that shows the tight association of DNA methylation with low expression and hypomethylation with higher levels of 14-3-3 $\sigma$ expression $[40,42]$.

3.6. Gene Reactivation with 5-Aza-Deoxycytidine. The mRNA expression and sodium bisulfite DNA sequencing data alone shows a potential association but does not fully establish a cause and effect relationship between cytosine methylation and maspin and 14-3-3 $\sigma$ gene expression. Therefore we investigated whether we could induce maspin and 14-3-3 $\sigma$ expression by treating the maspin and 143-3 $\sigma$ negative SNM83 chondrocyte cells and the CS8E chondrosarcoma cells with the DNA methyltransferase

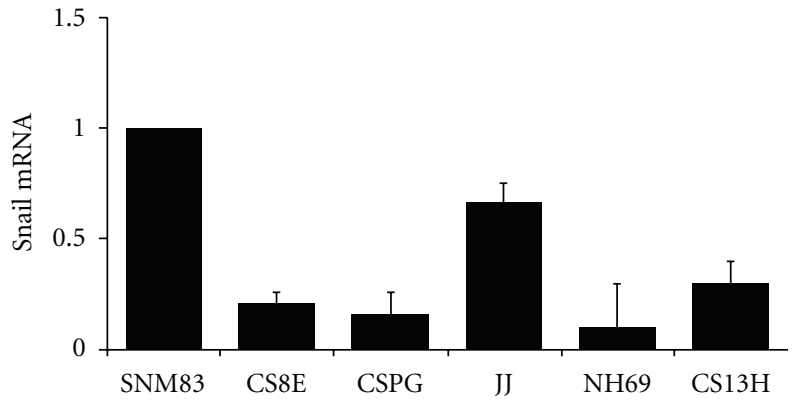

Figure 7: Snail mRNA expression is downregulated in human chondrosarcomas. All five chondrosarcoma cell lines showed a significant decrease ranging from 1.5 - to a 10 -fold decrease in snail mRNA expression when compared to the normal SNM83 chondrocyte cell line as determined by real-time PCR using $\Delta \Delta \mathrm{CT}$ relative quantification method. Expression is normalized to SNM83 chondrocyte expression.

inhibitor 5-aza-2'-deoxycytidine (5-aza-dC). After 120 hours of $5 \mu \mathrm{M} 5$-aza-dC both the SNM83 and CS8E cells showed a significant increase from almost undetectable levels of maspin and $14-3-3 \mu$ to crisp mRNA expression when compared to the untreated controls as shown in Figure 6. These data are consistent with previous reports of induced maspin and 14-3-3 $\sigma$ expression following 5-aza-dC treatment of hypermethylated and nonexpressing cell lines $[21,32,41,49]$.

3.7. Loss of Snail mRNA Expression in Chondrosarcomas. To begin to assess the potential underlying molecular mecha$\operatorname{nism}(\mathrm{s})$ for the apparent epigenetic switch in lineage-specific gene expression we observed and we measured snail mRNA expression, since snail has been reported to participate in the MET. Interestingly, snail mRNA expression was significantly downregulated in all five chondrosarcoma cell lines when compared to the SNM83 normal chondrocytes, ranging from a 1.5 - to 10 -fold decrease in mRNA expression as shown in Figure 7. This decrease is supportive of our observation that E-cadherin and other epithelial-specific markers mRNAs were induced in the majority of human chondrosarcoma cell lines analyzed and is noteworthy because of recent reports showing that stable RNA interference of snail can lead to a MET transition [25].

\section{Discussion}

In this study we examined whether epigenetic changes are associated with a mesenchymal to epithelial-like transition in chondrosarcomas. To first investigate whether that our chondrosarcoma cells were acquiring more epithelial-like characteristics we queried the expression of four separate epithelial markers: E-cadherin, desmocollin 3, maspin, and 14-3-3 $\sigma$. All of these genes have been shown to be deregulated in association with cytosine methylation and are involved with the malignant progression of many cancers [20-24, 50-52]. Therefore, two of these genes, maspin and $14-3-3 \sigma$, were further examined as representatives 
for epigenetic alterations. We identified the acquisition of expression of all four epithelial-specific markers in four of the five chondrosarcoma cell lines examined. Moreover, the robust acquisition of maspin and 14-3-3 $\sigma$ expression in chondrosarcomas is associated with a significant loss of DNA methylation at those loci when compared to normal SNM83 chondrocyte cell strain.

The acquisition of the epithelial markers E-cadherin and desmocollin 3 in four of the five chondrosarcoma cell lines is consistent with reports showing that sarcomas can to some degree transition through MET from their parental cell lineage $[48,53]$. The acquisition of E-cadherin is interesting because of the numerous reports indicating that downregulation of E-cadherin, frequently by aberrant methylation, is a hallmark of EMT. An important mediator of EMT and E-cadherin downregulation in cancer is the zinc finger transcription factor snail. An example of snail's important role in EMT and control of E-cadherin has been shown in snail knock-out mice which show embryonic lethality, and the embryos fail to complete EMT, forming an altered mesodermal layer while still retaining E-cadherin expression. Among the chondrosarcoma cell lines assessed here, all five showed a significant decrease in the mRNA expression of the snail transcription factor. Although the amount of decrease in snail expression was not predictive of the fold mRNA increase of E-cadherin, the downregulation of snail is suggestive of a less repressed E-cadherin and therefore could help to explain the observed increase of E-cadherin in our chondrosarcoma cells. In recent reports snail has also been investigated as an effector of the epigenetic changes observed in the downregulation of E-cadherin. It has been shown in these reports that snail binds to the E-boxes of the E-cadherin promoter and helps to recruit both histone deacetylase 1 (HDAC1) and DNA methyltransferase 1 (DNMT1). Indeed when snail was stably overexpressed in Hep3b cells the Ecadherin promoter became hypermethylated and histone $\mathrm{H} 3$ and $\mathrm{H} 4$ acetylation were decreased [46]. In support of this, a similar study by Cano et al. showed that stable interference of snail mRNA in snail overexpressing Madin Darby canine kidney (MDCK) cells led to a full MET and re-expression of E-cadherin. They extended and confirmed these results when they stably knocked down snail in two mouse epidermal carcinoma cell lines with similar results [54].

The acquired expression in our chondrosarcoma cells of four epithelial markers that have been shown in other cancers to be deregulated by promoter methylation, taken together with the downregulation of snail, led us to examine whether epigenetic changes could be associated with this MET-like transition in the chondrosarcoma cell lines assessed. To do this we compared the methylation status of maspin and 14$3-3 \sigma$ in chondrosarcoma cells that acquired the expression of these markers to their nonexpressing normal counterpart, the SNM83 chondrocyte cell line. We report here that acquisition of both maspin and 14-3-3 $\sigma$ in chondrosarcoma cell lines is tightly associated with aberrant hypomethylation of their $\mathrm{CpG}$ islands and that expression of both epithelial markers could be induced in a nonexpressing chondrosarcoma cell line by addition of the DNA methyltransferase inhibitor 5-Aza-dC. These findings are consistent with the epigenetic control of these loci documented in recent studies of multiple normal and cancer cell types $[21,22,34,55]$. The acquisition of maspin and 14-3-3 $\sigma$ in chondrosarcomas and other cancers, while still seemingly paradoxical to its role as a tumor suppressor, may be considered as a loss of epigenetic control. However, this may be better viewed as an epigenetic switch whereby the cancer cell, during progression, coopts the normal epigenetic mechanism(s) to propagate diverse cell types of differing lineage specificities. An example of this epigenetic switch may occur in solid tumors such as in colorectal cancer which uses the EMT transition to acquire a more metastatic phenotype but subsequently undergoes the reciprocal MET at the site of metastasis to reacquire, at least in part, the phenotype of the originating tumor [10]. This phenotypic reversion may confer a selective advantage to its new environment at the site of metastasis and thus allow for more successful colonization. The dynamic interconversions between EMT and MET in malignant progression cannot simply be explained by irreversible genetic alterations. These interconversions are suggestive of epigenetic mechanisms playing a role in these transitions because epigenetic changes, in contrast to irreversible genetic changes, are not permanent and allow a tumor cell more plasticity to alter its gene expression to adapt to different environments that can ultimately lead to phenotypic changes.

One of the ways a tumor cell can accomplish this epigenetic switch is through variable DNA methylation of the $\mathrm{CpG}$ sites in the transcriptional control regions of genes. Specific examples of this switch in maspin and 14-3-3 $\sigma$ expression have been documented to occur both in ovarian and breast carcinomas. It is interesting to note that maspin expression is silenced during breast cancer progression, but activated during ovarian cancer progression $[34,35]$. Ovarian surface epithelial cells being derived from the mesoderm activate maspin expression through DNA hypomethylation as they transition through MET [56]. Conversely, breast carcinomas typically silence maspin expression through hypermethylation and undergo the EMT to become more mesenchymal [32, 40,57]. It is also noteworthy to mention that snail expression has been shown to be decreased in ovarian cancer cells during MET and to increase in breast cancer cells during EMT $[58,59]$. To speculate that snail is affecting the epigenetic control of maspin expression in these cancers as well as in our chondrosarcoma cells is intriguing but has yet to be examined. However a bioinformatics search of both maspin and 14-3-3 $\sigma$ promoters reveals putative snail binding sites but further research is needed to elucidate any direct interaction. These examples may however help to explain the paradoxical gain of expression of maspin and 14-3-3 $\sigma$ in chondrosarcomas as well as in pancreatic and ovarian cancers. While epigenetic changes in the expression of maspin, 14-3-3 $\sigma$, desmocollin 3, and Ecadherin in chondrosarcoma cells and in other cancers are associated with the EMT or MET transitions, the extent to which they are a contributing factor to these process remains to be determined. Nevertheless, they may provide new biomarkers for differential diagnosis of cartilaginous 
diseases and provide better insights into how cells loss lineage maintenance in cancer.

In addition to showing an epigenetic mechanism for 143-3 $\sigma$ upregulation in chondrosarcoma cells it is interesting to speculate on what affects this acquired expression could have on treatment. The abundant expression of 14-3-3 $\sigma$ might help to confer the drug and radiation resistance commonly found in the treatment of chondrosarcomas [4, 40,60]. In a recent study 14-3-3 $\sigma$ was identified as an important contributor to drug resistance in human breast and pancreas cancer cells, and the exogenous overexpression of 14-3-3 $\sigma$ led to a greater resistance to chemotherapeutics and radiation $[60,61]$.

\section{Conclusion}

In summary we show that chondrosarcoma cells acquire four epithelial-specific markers maspin, 14-3-3 $\sigma$, desmocollin 3, and E-cadherin, which when taken together, is suggestive of chondrosarcoma cells undergoing to some degree an MET transition. We also report that all of the chondrosarcomas examined showed a significant downregulation of the snail transcription factor which may help to explain the reacquisition of E-cadherin and MET-like transition in our cell lines. The reports that snail has been shown to act as an epigenetic repressor of E-cadherin by recruitment of histone deacetylase 1 and DNA methyltransferase led us to examine whether additional changes in the epigenetic maintenance

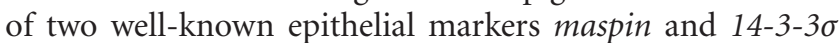
were occurring during this MET-like transition. We show here for the first time that chondrosarcoma cells acquire both maspin and 14-3-3 $\sigma$ mRNA expression which is associated with vastly decreased DNA methylation of their genes. The acquisition of expression of these genes could be playing a role in malignant progression, or their expression could simply be biomarkers of progression. Expression of these genes, especially $14-3-3 \sigma$, could also be contributing to some of the characteristics of chondosarcomas such as resistance to chemotherapy and radiation [40]. We now report that epigenetic changes through loss of DNA methylation occur

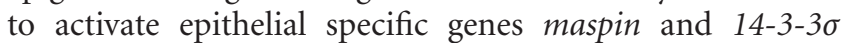
and that they are associated with the upregulation of $E$ cadherin, desmocollin 3 and the downregulation of snail during the transition of chondrocytes to chondrosarcomas. These epigenetic changes have not been extensively studied in MET, and this new knowledge could lead to more insight into the mechanisms underlying this important process, as well as aid in identifying new markers for better staging, diagnosing, and treating chondrosarcomas.

\section{Abbreviations}

5-Aza-dC: 5-Aza-2'-deoxycytidine

LOH: Loss of heterozygosity

MET: Mesenchymal to Epithelial transition

EMT: Epithelial to Mesenchymal transition

E-cad: E-Cadherin

DSC3: $\quad$ Desmocollin 3.

\section{Acknowledgments}

This paper was supported by NIH grant R01 CA73612 and R01 CA115438 to F. E. Domann. M. L. T. Teoh received salary support from Susan G. Komen for the Cure award, A. J. Case received support from DOD PC073831, M. J. Provenzano received salary support from T32 DC000040, and J. A. Martin received support through an award from The Ben Ling Foundation. The authors would also like to thank the University of Iowa DNA Sequencing Core facility supported in part by P30CA086862. Matthew P. Fitzgerald and Francoise Gourronc contributed equally to this work.

\section{References}

[1] H. D. Dorfman and B. Czerniak, "Bone cancers," Cancer, vol. 75, no. 1, pp. 203-210, 1995.

[2] S. Gitelis, F. Bertoni, P. Picci, and M. Campanacci, "Chondrosarcoma of bone. The experience at the Istituto Ortopedico Rizzoli," Journal of Bone and Joint Surgery-Series A, vol. 63, no. 8, pp. 1248-1257, 1981.

[3] R. M. Terek, G. K. Schwartz, K. Devaney et al., "Chemotherapy and P-glycoprotein expression in chondrosarcoma," Journal of Orthopaedic Research, vol. 16, no. 5, pp. 585-590, 1998.

[4] F. Moussavi-Harami, A. Mollano, J. A. Martin et al., "Intrinsic radiation resistance in human chondrosarcoma cells," Biochemical and Biophysical Research Communications, vol. 346, no. 2, pp. 379-385, 2006.

[5] A. M. Cleton-Jansen, H. M. van Beerendonk, H. J. Baelde, J. V. G. M. Bovée, M. Karperien, and P. C. W. Hogendoorn, "Estrogen signaling is active in cartilaginous tumors: implications for antiestrogen therapy as treatment option of metastasized or irresectable chondrosarcoma," Clinical Cancer Research, vol. 11, no. 22, pp. 8028-8035, 2005.

[6] H. M. van Beerendonk, L. B. Rozeman, A. H. M. Taminiau et al., "Molecular analysis of the INK4A/INK4A-ARF gene locus in conventional (central) chondrosarcomas and enchondromas: indication of an important gene for tumour progression," Journal of Pathology, vol. 202, no. 3, pp. 359-366, 2004.

[7] M. Röpke, C. Boltze, H. W. Neumann, A. Roessner, and R. Schneider-Stock, "Genetic and epigenetic alterations in tumor progression in a dedifferentiated chondrosarcoma," Pathology Research and Practice, vol. 199, no. 6, pp. 437-444, 2003.

[8] T. Tsuchiya, T. Osanai, A. Ogose et al., "Methylation status of EXT1 and EXT2 promoters and two mutations of EXT2 in chondrosarcoma," Cancer Genetics and Cytogenetics, vol. 158, no. 2, pp. 148-155, 2005.

[9] P. Ouyang, "An in vitro model to study mesenchymalepithelial transformation," Biochemical and Biophysical Research Communications, vol. 246, no. 3, pp. 771-776, 1998.

[10] H. Hugo, M. L. Ackland, T. Blick et al., "Epithelialmesenchymal and mesenchymal-epithelial transitions in carcinoma progression," Journal of Cellular Physiology, vol. 213, no. 2, pp. 374-383, 2007.

[11] C. L. Chaffer, E. W. Thompson, and E. D. Williams, "Mesenchymal to epithelial transition in development and disease," Cells Tissues Organs, vol. 185, no. 1-3, pp. 7-19, 2007.

[12] T. Naka, Y. Iwamoto, N. Shinohara, M. Ushijima, H. Chuman, and M. Tsuneyoshi, "Expression of c-met proto-oncogene product (c-MET) in benign and malignant bone tumors," Modern Pathology, vol. 10, no. 8, pp. 832-838, 1997.

[13] K. Scotlandi, N. Baldini, M. Oliviero et al., "Expression of met/hepatocyte growth factor receptor gene and malignant 
behavior of musculoskeletal tumors," American Journal of Pathology, vol. 149, no. 4, pp. 1209-1219, 1996.

[14] M. Jeffers, S. Rong, and G. F. Woude, "Hepatocyte growth factor/scatter factor-met signaling in tumorigenicity and invasion/metastasis," Journal of Molecular Medicine, vol. 74, no. 9, pp. 505-513, 1996.

[15] I. Tsarfaty, S. Rong, J. H. Resau, S. Rulong, P. P. Da Silva, and G. F. Vande Woude, "The Met proto-oncogene mesenchymal to epithelial cell conversion," Science, vol. 263, no. 5143, pp. 98-101, 1994.

[16] M. Darmon, J. F. Nicolas, and D. Lamblin, "5-Azacytidine is able to induce the conversion of teratocarcinoma-derived mesenchymal cells into epithelia cells," EMBO Journal, vol. 3, no. 5, pp. 961-967, 1984.

[17] C. S. Bathula, S. H. Garrett, X. D. Zhou, M. A. Sens, D. A. Sens, and S. Somji, "Cadmium, vectorial active transport, and MT-3-Dependent regulation of cadherin expression in human proximal tubular cells," Toxicological Sciences, vol. 102, no. 2, pp. 310-318, 2008.

[18] M. Jorda, A. Vinyals, A. Marazuela et al., "Id-1 is induced in MDCK epithelial cells by activated Erk/MAPK pathway in response to expression of the Snail and E47 transcription factors," Experimental Cell Research, vol. 313, no. 11, pp. 23892403, 2007.

[19] M. A. Horswill, M. Narayan, D. J. Warejcka, L. A. Cirillo, and S. S. Twining, "Epigenetic silencing of maspin expression occurs early in the conversion of keratocytes to fibroblasts," Experimental Eye Research, vol. 86, no. 4, pp. 586-600, 2008.

[20] C. Boltze, R. Schneider-Stock, C. Quednow et al., "Silencing of the maspin gene by promoter hypermethylation in thyroid cancer," International Journal of Molecular Medicine, vol. 12, no. 4, pp. 479-484, 2003.

[21] M. Fitzgerald, M. Oshiro, N. Holtan et al., "Human pancreatic carcinoma cells activate maspin expression through loss of epigenetic control," Neoplasia, vol. 5, no. 5, pp. 427-436, 2003.

[22] Y. Yatabe, T. Mitsudomi, and T. Takahashi, "Maspin expression in normal lung and non-small-cell lung cancers: cellular property-associated expression under the control of promoter DNA methylation," Oncogene, vol. 23, no. 23, pp. 4041-4049, 2004.

[23] R. Henrique, C. Jerónimo, M. O. Hoque et al., "Frequent 143-3 $\sigma$ promoter methylation in benign and malignant prostate lesions," DNA and Cell Biology, vol. 24, no. 4, pp. 264-269, 2005.

[24] A. Benzinger, N. Muster, H. B. Koch, J. R. Yates, and H. Hermeking, "Targeted proteomic analysis of 14-3-3 $\sigma$, a p53 effector commonly silenced in cancer," Molecular and Cellular Proteomics, vol. 4, no. 6, pp. 785-795, 2005.

[25] A. Cano, M. A. Pérez-Moreno, I. Rodrigo et al., "The transcription factor Snail controls epithelial-mesenchymal transitions by repressing E-cadherin expression," Nature Cell Biology, vol. 2, no. 2, pp. 76-83, 2000.

[26] Z. Zou, A. Anisowicz, M. J. C. Hendrix et al., "Maspin, a serpin with tumor-suppressing activity in human mammary epithelial cells," Science, vol. 263, no. 5146, pp. 526-529, 1994.

[27] R. Sager, S. Sheng, P. Pemberton, and M. J. C. Hendrix, "Maspin: a tumor suppressing serpin," Advances in Experimental Medicine and Biology, vol. 425, pp. 77-88, 1997.

[28] M. Zhang, O. Volpert, Y. H. Shi, and N. Bouck, "Maspin is an angiogenesis inhibitor," Nature Medicine, vol. 6, no. 2, pp. 196-199, 2000.

[29] B. W. Futscher, M. M. Oshiro, R. J. Wozniak et al., "Role for DNA methylation in the control of cell type-specific maspin expression," Nature Genetics, vol. 31, no. 2, pp. 175-179, 2002.
[30] J. S. Schaefer and M. Zhang, "Role of maspin in tumor metastasis and angiogenesis," Current Molecular Medicine, vol. 3, no. 7, pp. 653-658, 2003.

[31] M. Zhang, "Multiple functions of maspin in tumor progression and mouse development," Frontiers in Bioscience, vol. 9, pp. 2218-2226, 2004.

[32] F. E. Domann, J. C. Rice, M. J. C. Hendrix, and B. W. Futscher, "Epigenetic silencing of maspin gene expression in human breast cancers," International Journal of Cancer, vol. 85, no. 6 , pp. 805-810, 2000.

[33] K. Wada, C. Maesawa, T. Akasaka, and T. Masuda, "Aberrant expression of the maspin gene associated with epigenetic modification in melanoma cells," Journal of Investigative Dermatology, vol. 122, no. 3, pp. 805-811, 2004.

[34] S. L. Rose, M. P. Fitzgerald, N. O. White et al., "Epigenetic regulation of maspin expression in human ovarian carcinoma cells," Gynecologic Oncology, vol. 102, no. 2, pp. 319-324, 2006.

[35] A. K. Sood, M. S. Fletcher, L. M. Gruman et al., "The paradoxical expression of Maspin in ovarian carcinoma," Clinical Cancer Research, vol. 8, no. 9, pp. 2924-2932, 2002.

[36] H. J. Son, T. S. Sohn, S. Y. Song, J. H. Lee, and J. C. Rhee, "Maspin expression in human gastric adenocarcinoma," Pathology International, vol. 52, no. 8, pp. 508-513, 2002.

[37] G. L. Prasad, E. M. Valverius, E. McDuffie, and H. L. Cooper, "Complementary DNA cloning of a novel epithelial cell marker protein, HME1, that may be down-regulated in neoplastic mammary cells," Cell growth \& Differentiation, vol. 3, no. 8, pp. 507-513, 1992.

[38] H. Hermeking, C. Lengauer, K. Polyak et al., "14-3-3 $\sigma$ is a p53regulated inhibitor of G2/M progression,” Molecular Cell, vol. 1, no. 1, pp. 3-11, 1997.

[39] W. R. Taylor and G. R. Stark, "Regulation of the G2/M transition by p53," Oncogene, vol. 20, no. 15, pp. 1803-1815, 2001.

[40] A. T. Ferguson, E. Evron, C. B. Umbricht et al., "High frequency of hypermethylation at the 14-3-3 $\sigma$ locus leads to gene silencing in breast cancer," Proceedings of the National Academy of Sciences of the United States of America, vol. 97, no. 11, pp. 6049-6054, 2000.

[41] N. Iwata, H. Yamamoto, S. Sasaki et al., "Frequent hypermethylation of CpG islands and loss of expression of the 14-3-3 $\sigma$ gene in human hepatocellular carcinoma," Oncogene, vol. 19, no. 46, pp. 5298-5302, 2000.

[42] A. Guweidhi, J. Kleeff, N. Giese et al., "Enhanced expression of 14-3-3sigma in pancreatic cancer and its role in cell cycle regulation and apoptosis," Carcinogenesis, vol. 25, no. 9, pp. 1575-1585, 2004.

[43] T. Sano, H. Shimooka, P. Weixa et al., "Immunohistochemical expression of 14-3-3 sigma protein in various histological subtypes of uterine cervical cancers," Pathology International, vol. 54, no. 10, pp. 743-750, 2004.

[44] M. M. Oshiro, C. J. Kim, R. J. Wozniak et al., "Epigenetic silencing of DSC3 is a common event in human breast cancer," Breast Cancer Research, vol. 7, no. 5, pp. R669-R680, 2005.

[45] M. T. Debies and D. R. Welch, "Genetic basis of human breast cancer metastasis," Journal of Mammary Gland Biology and Neoplasia, vol. 6, no. 4, pp. 441-451, 2001.

[46] S. O. Lim, J. M. Gu, M. S. Kim et al., "Epigenetic changes induced by reactive oxygen species in hepatocellular carcinoma: methylation of the E-cadherin promoter," Gastroenterology, vol. 135, no. 6, pp. 2128-2140, 2008.

[47] J. A. Martin, E. Forest, J. A. Block et al., "Malignant transformation in human chondrosarcoma cells supported by 
telomerase activation and tumor suppressor inactivation," Cell Growth and Differentiation, vol. 13, no. 9, pp. 397-407, 2002.

[48] M. M. Oshiro, B. W. Futscher, A. Lisberg et al., "Epigenetic regulation of the cell type-specific gene 14-3-3 $\sigma$," Neoplasia, vol. 7, no. 9, pp. 799-808, 2005.

[49] S. Murai, C. Maesawa, T. Masuda, and T. Sugiyama, "Aberrant maspin expression in human endometrial cancer," Cancer Science, vol. 97, no. 9, pp. 883-888, 2006.

[50] Y. Akiyama, C. Maesawa, S. Ogasawara, M. Terashima, and T. Masuda, "Cell-type-specific repression of the maspin gene is disrupted frequently by demethylation at the promoter region in gastric intestinal metaplasia and cancer cells," American Journal of Pathology, vol. 163, no. 5, pp. 1911-1919, 2003.

[51] M. Gasco, A. K. Bell, V. Heath et al., "Epigenetic inactivation of 14-3-3 $\sigma$ in oral carcinoma: association with p16 silencing and human papillomavirus negativity," Cancer Research, vol. 62, no. 7, pp. 2072-2076, 2002.

[52] J. M. A. Moreira, G. Ohlsson, F. E. Rank, and J. E. Celis, "Down-regulation of the tumor suppressor protein 14-3-3 $\sigma$ is a sporadic event in cancer of the breast," Molecular and Cellular Proteomics, vol. 4, no. 4, pp. 555-569, 2005.

[53] T. Saito, M. Nagai, and M. Ladanyi, "SYT-SSX1 and SYT-SSX2 interfere with repression of E-cadherin by snail and slug: a potential mechanism for aberrant mesenchymal to epithelial transition in human synovial sarcoma," Cancer Research, vol. 66, no. 14, pp. 6919-6927, 2006.

[54] D. Olmeda, M. Jordá, H. Peinado, A. Fabra, and A. Cano, "Snail silencing effectively suppresses tumour growth and invasiveness," Oncogene, vol. 26, no. 13, pp. 1862-1874, 2007.

[55] F. E. Domann and B. W. Futschert, "Flipping the epigenetic switch," American Journal of Pathology, vol. 164, no. 6, pp. 1883-1886, 2004.

[56] N. Auersperg, J. Pan, B. D. Grove et al., "E-cadherin induces mesenchymal-to-epithelial transition in human ovarian surface epithelium," Proceedings of the National Academy of Sciences of the United States of America, vol. 96, no. 11, pp. 6249-6254, 1999.

[57] Y. Kang and J. Massagué, "Epithelial-mesenchymal transitions: twist in development and metastasis," Cell, vol. 118, no. 3, pp. 277-279, 2004.

[58] N. K. Kurrey, K. Amit, and S. A. Bapat, "Snail and Slug are major determinants of ovarian cancer invasiveness at the transcription level," Gynecologic Oncology, vol. 97, no. 1, pp. 155-165, 2005.

[59] D. Olmeda, G. Moreno-Bueno, J. M. Flores, A. Fabra, F. Portillo, and A. Cano, "SNAI1 is required for tumor growth and lymph node metastasis of human breast carcinoma MDAMB-231 cells," Cancer Research, vol. 67, no. 24, pp. 1172111731, 2007.

[60] Y. Liu, H. Liu, B. Han, and J. T. Zhang, "Identification of 14-3$3 \sigma$ as a contributor to drug resistance in human breast cancer cells using functional proteomic analysis," Cancer Research, vol. 66, no. 6, pp. 3248-3255, 2006.

[61] P. Sinha, G. Hütter, E. Köttgen, M. Dletel, D. Schadendorf, and H. Lage, "Increased expression of epidermal fatty acid binding protein, cofilin, and 14-3-3- $\sigma$ (stratifin) detected by two-dimensional gel electrophoresis, mass spectrometry and microsequencing of drug-resistant human adenocarcinoma of the pancreas," Electrophoresis, vol. 20, no. 14, pp. 2952-2960, 1999. 


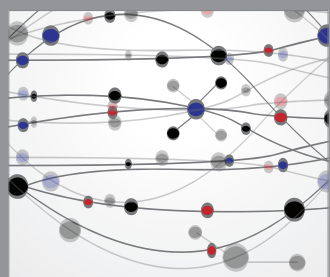

The Scientific World Journal
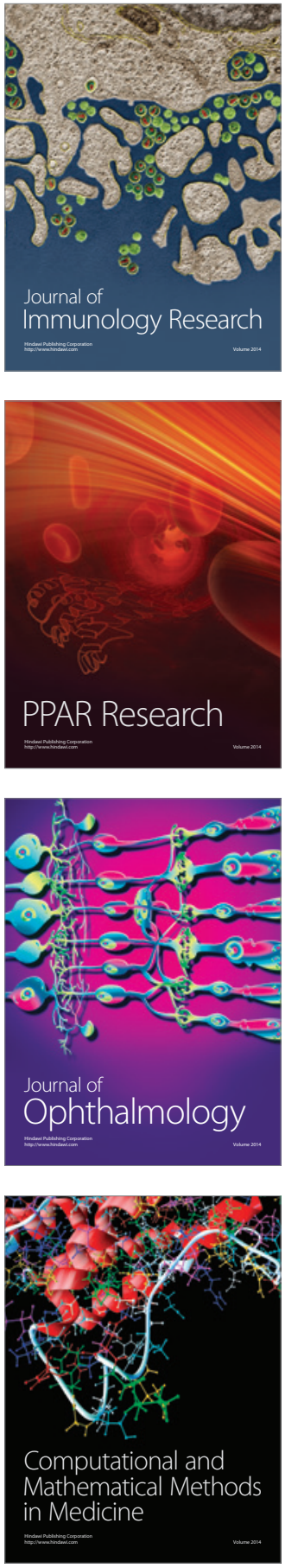

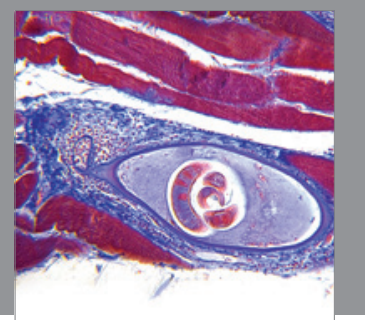

Gastroenterology

Research and Practice
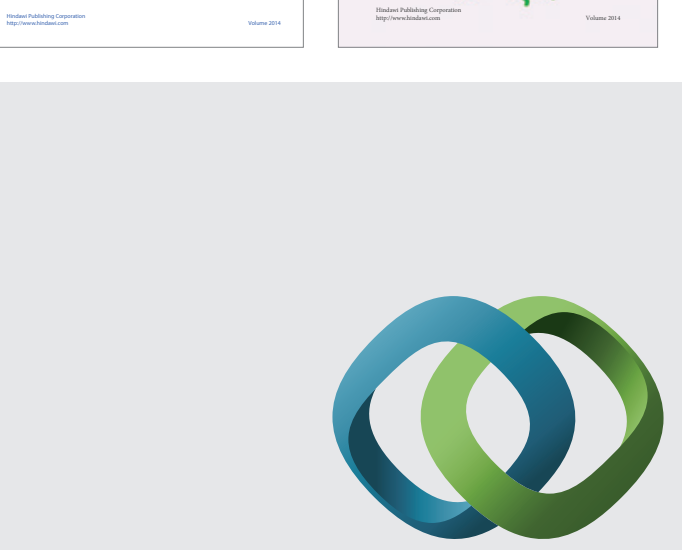

\section{Hindawi}

Submit your manuscripts at

http://www.hindawi.com
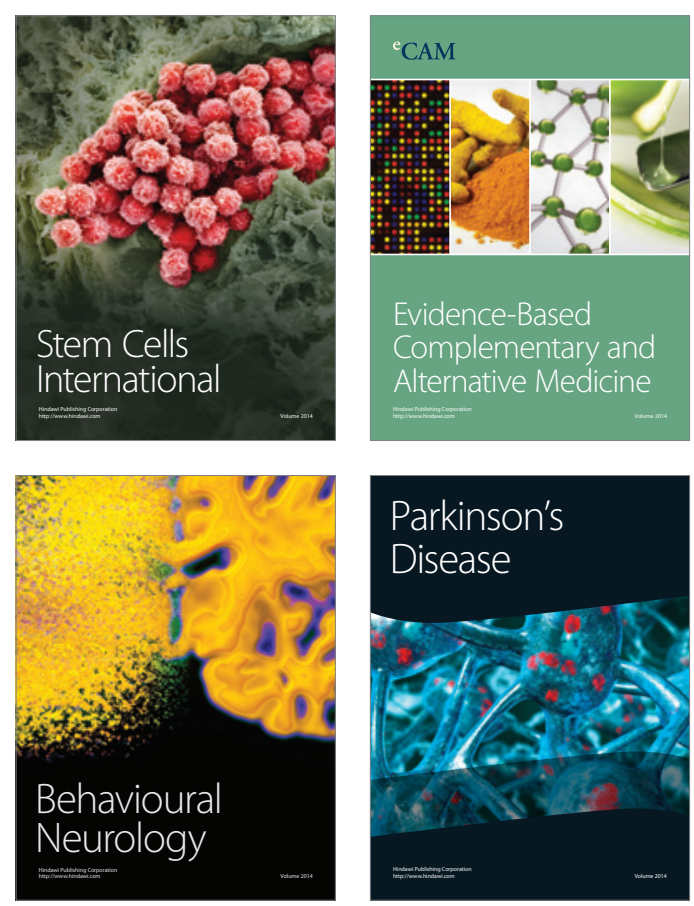

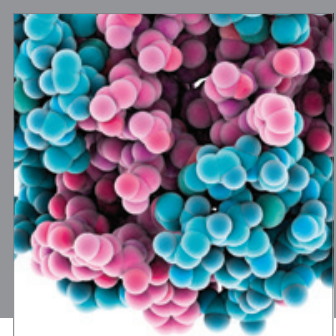

Journal of
Diabetes Research

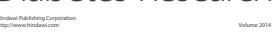

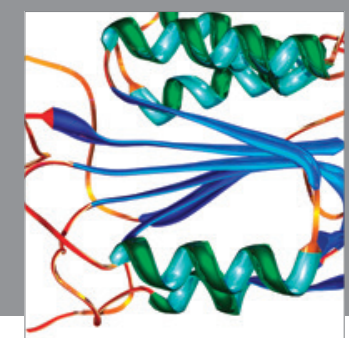

Disease Markers
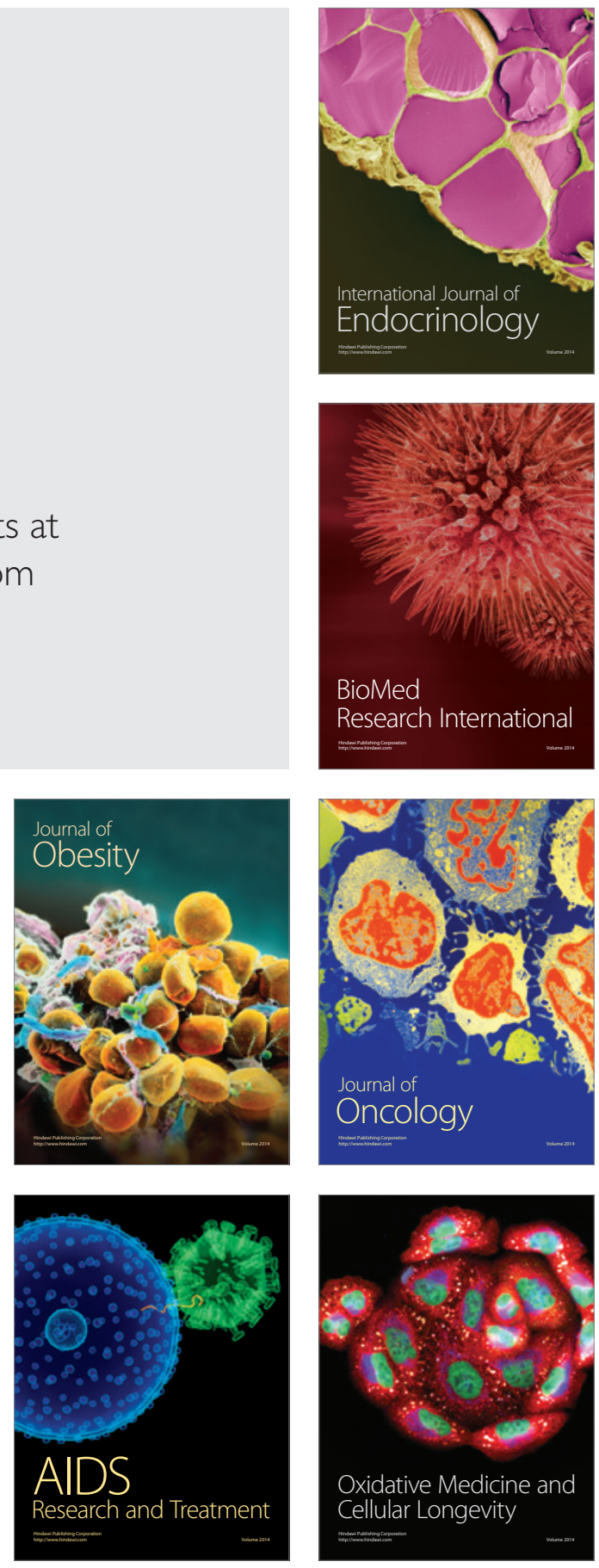